\title{
Information communication technology in the form of an expert system shell as a cognitive tool to facilitate higher-order thinking
}

\author{
Gary W. Collins \\ Tshwane University of Technology, South Africa
}

Johan G. Knoetze

University of Pretoria, South Africa

\begin{abstract}
Information communication technology is capable of contributing supplementary teaching and learning strategies that can be used to address various educational challenges faced by higher education. Students who enter South African higher education institutions are often academically under-prepared and have not developed the cognitive skills required to engage in meaningful learning. When students build expert systems they are required to demonstrate the reasoning of an expert and to exhibit an understanding of causal relationships and procedural knowledge. This study formulated design principles in the form of conjectures and principles related to a learning environment that uses technology as a cognitive tool in the form of an expert system shell to promote higher-order thinking skills. The conjectures and principles formulated during this study are expressed in terms of the characteristics, procedures and arguments associated with a learning environment that uses technology in the form of an expert system shell to facilitate higher-order thinking. These conjectures and principles were separated into seven interrelated clusters: initial exposure, guided discovery learning, designing the expert system on paper, creating domain awareness, linking conceptual understanding to a representation of that understanding, hands-on development, and problem engagement.
\end{abstract}

\section{Introduction}

Higher education in South Africa faces many challenges. Among these are the "general lack of academic preparedness" of students who typically enter South African higher education institutions (Jaffer, Ng'ambi, \& Czerniewicz 2007; p. 131). Due mainly to deficiencies in their schooling, these students often expect to be provided with answers and are not able to engage with learning material at a higher cognitive level. This under preparedness does not seem to be confined to the South African context and can be viewed as a global concern (Palermo, Marr, Oriel, Arthur, \& Johnston, 2012; Silburn, Earnest, Butcher, \& de Mori, 2008; Dzubak, 2005). Palermo et al. (2012) indicate that issues related to students' under preparedness for academic success at universities is a significant challenge in Australia, especially among students from disadvantaged backgrounds. They point out that "attrition rates in many universities are much higher than could be considered acceptable" and "Australian higher education lags behind other western countries in relation to access and attainment of equity groups" (Palermo et al., 2012; pp. 39-40).

Jaffer et al. (2007) point out that even though educational technology cannot address all the educational challenges faced by learning institutions, it has the potential to leverage and widen conventional teaching and learning activities under certain circumstances, and therefore influence the way in which students engage cognitively with material. Zhang (2013) supports this by proposing that technology based learning tools are increasingly being "incorporated into instructional activities to scaffold students learning" and have "demonstrated a great potential to improve learning "and assist educators in the achievement of various learning goals". When computers are used to actively engage students in a learning task, promote deep thinking and reflection, and allow students to articulate knowledge, they are said to be used as cognitive tools (Kennedy \& McNaught, 2001; p. 926)

The study reported on in this paper involves an iterative design research approach and aims to extend the understanding of what a learning environment that uses technology as a cognitive tool to encourage higherorder thinking in students who enter higher learning institutions may look like. Here the educational 
technology is in the form of an expert system shell that enables students to create external representations of their understanding in the form of functional expert systems.

\section{Background}

Many South African school leavers have not been provided with the necessary resources that are important to the development of cognitive skills (Fiske \& Ladd, 2005). They often come from environments that present them with very little that would stimulate thought that is beyond their direct experience (Fiske \& Ladd, 2005). The school setting is frequently not conducive to meaningful learning and students are often taught by under qualified teachers who lack the necessary skills to develop the learner's cognitive abilities (Stephen, Welman, \& Jordaan, 2004; Fiske \& Ladd, 2005). Rote learning, without very much effort at comprehension, often seems to be characteristic of their school experience (Stephen et al., 2004). Students are often more interested in passing exams than gaining knowledge, and feel as though they are being deprived of something when they are not simply provided with answers (Stephen et al., 2004).

Thanasoulas (2001) maintains that students who do not come from suitable educational backgrounds are unable to accurately understand and interpret information that is presented to them. Greater demands are made of students who enter higher education institutions. As a consequence, it is no longer adequate to simply reproduce information, these students are required to "participate in knowledge creation", rather than be "mere receptacles of inert knowledge" in order to achieve "higher order learning outcomes" (McLoughlin, 1999; p. 226). Resonance is found in Silburn et al.'s (2013; p. 13) study where they highlight the academic under preparedness of Australian students from a refugee background and point out that these students "require a higher level of encouragement and assistance particularly in their first year of undergraduate studies".

For computer technology to support cognition and encourage higher learning outcomes it is necessary for educators to "reconceptualise the way that they are used" (Jonassen, 2006; p. xiii). Gilakjani, Leong and Ismail (2013; p. 49) propose that "technology provides many new opportunities for issues like learning styles, student-centered instruction and promotion of higher-level thinking", and when used in a constructivist learning environment, technology becomes a tool "used by the learners to create a product to be presented to teachers and fellow students so that they may review, learn, or critique in a collaborative manner".

\section{Computer technology as a cognitive tool}

Gilakjani et al. (2013; p. 58) maintain that technology is being used effectively in a classroom context "where the technology supports and scaffolds the learning rather than being the object or derivative of the learning". They point out that there is a clear distinction "between learning from computers and learning with computers". Jonassen, Carr and Yueh (1998; p. 24) argue that technology should be used as a tool that learners learn with, not from, rather than a medium of communication that acts like a teacher that instructs the learner. This would allow the learner to act as a designer and the computer to function as a tool that interprets and organizes their personal knowledge (Jonassen et al., 1998). Computers would then function as an extension of the mind that supports and represents cognitive processes (van Joolingen, 1999). When computers are used as instruments that support cognitive processes that extend people's cognitive capacity, they can be described as cognitive tools (van Joolingen, 1999). A computer based cognitive tool is a learning tool that allows students to "articulate their thought processes, solve problems, engage in collaborative processes and think" (Kennedy \& McNaught, 2007; p. 926). Cognitive tools allow students to perform the role of designer and encourages them to solve problems by "analyzing, accessing, interpreting and organizing their personal knowledge" (Kennedy \& McNaught, 2007). Using computer technology as a cognitive tool is expected to encourage "critical thinking and higher-order thinking in students" (Kennedy \& McNaught, 2007, p. 926). 


\section{Cognitive tools as an intellectual partner}

When using cognitive tools, learners become intellectually more capable than they would otherwise be, as the specific functions that the tool is more suited to are made the responsibility of the cognitive tool (Jonassen, 2006). Kirscher and Wopereis (2003; p. 110) describe cognitive tools as "intellectual partners" and as "a partner in the learning process, they are responsible for that which they can perform best". Liu, Yuen, Horton, Lee, Toprac and Bogard (2013; p. 2) expand on this when they state that for "learners who lack welldeveloped knowledge structures and problem solving strategies, cognitive tools can provide essential scaffolds that support their solving of complex problems". Cognitive tools can serve to reduce the cognitive load associated with problem solving activities and increase "high level cognitive processes".

Technology serving as an intellectual partner does not mean that these tools reduce the amount of information processing required of the learner, but rather that they support learning by allowing the learner to make effective use of their mental efforts (Jonassen, 2006; Jonassen et al., 1998; Kirscher \& Wopereis, 2003). Jonassen (2006; p. 21) puts forward that this is because students cannot use cognitive tools "without thinking deeply about the content they are learning".

\section{Conceptual change and meaningful learning}

Meaningful learning typically involves conceptual change (Vosniadou, 2008) Conceptual change takes place when learners "change their understanding of the concepts they use and of conceptual frameworks that encompass them" (Jonassen, 2006; p. 4). Conceptual change may be viewed as, not merely the enrichment of knowledge, but rather as a learning process "that requires the significant reorganization of existing knowledge structures" (Vosniadou, Ioannides, Dimitrakopoulou, \& Papademetriou, 2001; p. 383).

It is unlikely that conceptual change will take place when a learner engages with information at a superficial level or when an attempt is being made to simply memorize the information for the purpose of an examination (Jonassen, 2006). Conceptual change takes place when learners participate in tasks that require conceptualization (Jonassen, 2006). More meaningful learning may take place when learners "use computers to apply higher-order skills such as solving simulations rather than drill and practice exercises" (Gilakjani et al., 2013; p. 52). Metacognition is an important requirement of conceptual change. This involves learners "thinking about their own cognition "and making a conscious effort "to reorganize their own understanding" (Liu et al., 2013; p. 2).

\section{Using computer technology to model understanding}

Mental models "are cognitive representations of external reality" and exist "within the mind and are therefore not available for direct inspection or measurement" (Jones, Ross, Lynam, Perez, \& Leitch, 2011; p. 4). Discovering ways of "eliciting a mental model" poses a significant challenge to those "interested in using the construct as a means to gain insight into people's internal representations of the world" (Jones et al., 2011; p. 4). Cognitive tools are able to engage learners in such a way that they construct their own knowledge by building mental models that "facilitate intense cognitive and social activities that result in conceptual change" (Jonassen, 2006; p. 23).

Unlike "cognitive and conceptual models that describe how users should represent a domain or system", mental models indicate the way learners actually understand the information (Jonassen, 1995; p. 184). Vosniadou (2007) expands on this by indicating that mental models have an important role to play in conceptual change as they can be "a point where new information enters the cognitive system in ways that can modify what we already know" (Vosniadou, 2007; p. 21).

Mental models develop in the mind of the individual learner and form the basis for external models that are represented in the "equations, diagrams, computer programs, and other representational media" used by 
learners to indicate their conceptualizations (Jonassen, 2006; p. 13). These models enable learners to construct and revise conceptual understanding, thereby initiating conceptual change (Jonassen, 2006).

\section{Modelling for articulating thinking and conceptualization}

Not only does modelling enable learners to articulate their thinking externally but it also allows them to visualize and evaluate the different elements of their conceptualizations (Jonassen, 2006). Comparing and contrasting the different models that each individual will inevitably construct will enable learners to achieve a deeper understanding of the concept being modelled. This will also allow the learner to recognize that each individual conceptualizes the external world differently and that the "activity of modeling can be used to test rival models" (Jonassen, 2006; p. 13). This, Jonassen suggests, is at the heart of conceptual change. Spector, Lockee, Smaldino and Herring $(2013 ;$ p. 17) propose that "the function of a mental model is to simulate actions in the mind, to assess their consequences, to interpret them, and to use these interpretations to make inferences". Mental models can be externalized by making use of "a particular symbol system (e.g. mind tools) and generate subjective plausibility with regard to complex phenomena to be understood and explained" (Spector, et al, 2013, p. 17).

Even though learning can be achieved by both using and constructing models, the construction of models is far more effective than merely using them. Jonassen (2006; p. 14) maintains that this is because when learners are expected to solve a problem or respond to complex conceptual questions, they are consistently inclined to build a mental model of the phenomena and use that model as the foundation for "prediction, inference, speculation, or experimentation". The external construction of a mental model enables learners to articulate their thinking in a concrete way.

\section{Expert systems}

Expert systems are computer-based tools that are developed "to function as intelligent aids to decision making" in a variety of situations (Jonassen \& Reeves, 1996; p.708). They are designed to mimic the reasoning a human expert will employ to solve a problem and will, therefore, be "artificial decision" makers (Jonassen et al., 1998; p.28). Jonassen and Reeves (1996; p. 708) point out that expert systems typically consist of a "knowledge base, inference engine, and user interface". The facts and rules that are incorporated into the design of the system make up the knowledge base, which is acted on by the inference engine "and current problem data to generate solutions" (Jonassen \& Reeves, 1996; p. 708). When the knowledge base does not contain sufficient information, the inference engine prompts the user to supply the system with the missing information. "The inference engine continues to seek information until it is able to reach a solution which the system then presents to the user" (Jonassen \& Reeves, 1996; p. 708-709). The inference engine will, therefore, be the logic unit of the system. Expert systems are most suited to problems to which the solutions comprise suggestions based on a combination of decisions (Jonassen \& Reeves, 1996).

\section{An expert system as a cognitive tool}

Jonassen and Reeves (1996; p. 709) maintain that the part of the expert system that makes it a cognitive tool is the knowledge base, as building the knowledge base requires the designer to express the "expertise that the system provides, not only in the form of facts but also rules". They go on to point out that the identification of the causal relationships and procedural knowledge that forms the foundation of the knowledge domain requires the designer to engage in higher-order thinking (Jonassen \& Reeves, 1996). To build the knowledge base the designer would need to express an understanding of causal knowledge (Jonassen et al., 1998). Jonassen (2006; p. 61) states that solving "all problems requires some form of causal reasoning" and the more complex the problem, "the more sophisticated the causal reasoning must be".

Jonassen and Reeves (1996) suggest that expert systems are one of the few mechanisms that explore procedural knowledge. This type of knowledge is often described in terms of IF -THEN rules and an understanding of the nature of a decision-making process will become more meaningful once learners identify 
the rules that apply to a particular domain (Jonassen \& Reeves, 1996). To be considered a cognitive tool, it is not sufficient for learners to be simply users of an expert system. They must be the designers of the system, as "simply using existing knowledge bases to get advice does not engage users as deeply as building a knowledge base to reflect their own thinking" (Jonassen \& Reeves, 1996; p. 708).

The purpose of this study was to formulate design principles in the form of conjectures and principles related to a learning environment that employed computer technology in the form of an expert system shell in order to facilitate higher-order thinking skills.

\section{Outlining the research design}

This study employed a research design that is based on many of the principles associated with educational design-based research. Reeves, McKenney and Herrington (2011; p. 56) propose that educational design research is an effective method of "solving real problems in practice and to advancing theoretical understanding as well". Design based research is considered particularly appropriate for the exploration of "technology-based initiatives" (Parker, 2011; p. 1).

With reference to appropriate literature and by making use of the researcher's creativity, a tentative design of a learning environment that uses computer technology as a cognitive tool in the form of an expert system shell was developed. This tentative design or prototype was placed before a design team that was purposively selected and included six experienced lecturers and instructional designers from a South African university of technology. This learning environment was improved and refined through a cyclic process that involved ten design sessions until it was considered substantially ready to be implemented in an authentic, real world educational setting. After each of the ten design sessions a focus group interview was held in order to obtain opinions, ideas and suggestions from the design team. These interviews were recorded and then transcribed verbatim. The modification and refinement of the prototype or tentative learning environment was based on a provisional or formative analysis of the focus group transcripts. A more comprehensive Grounded Theory analysis of the focus group interview transcripts held with the design team was conducted in order to discover and formulate design principles. These design principles were expressed in the form of conjectures and principles and followed a format that outlined the characteristics, procedures and arguments allied to these conjectures and principles. This format was based on Van den Akker's (as cited in Plomp, 2007; p. 20) suggestion for the formulation of design principles:

If you want to design intervention $\mathrm{X}$ [for the purpose/function $\mathrm{Y}$ in context $\mathrm{Z}$ ], then you are best advised to give that intervention the characteristics $\mathrm{A}, \mathrm{B}$, and $\mathrm{C}$ [substantive emphasis], and to do that via procedures $\mathrm{K}, \mathrm{L}$, and $\mathrm{M}$ [procedural emphasis], because of arguments $\mathrm{P}, \mathrm{Q}$, and $\mathrm{R}$.

Nieveen $(2007$; p. 89) stresses that a "set of well-articulated design principles" can "provide insight into the purpose and function of the intervention", the "key characteristics of the intervention", the guidelines for designing the intervention, the implementation conditions and the "theoretical and empirical arguments (proof) for the characteristics and procedural guidelines".

\section{Findings: A summary of the conjectures and principles}

Conjectures and principles were formulated from a grounded theory analysis of nine of the ten focus group interviews held with the design team. Even though the conjectures and principles all concern the characteristics, procedures and arguments associated with the same learning environment, their focus differed at times and can be separated into the following clusters:

- The students' initial exposure to the learning environment.

- The students discovering information and concepts on their own.

- Designing the expert system on paper.

- Creating subject domain awareness in the students. 
- Creating an awareness of the relationship between a conceptual understanding and a representation of that understanding.

- The students' hands on development of a functional expert system.

- The students' engagement with the problem statement.

A summary of these conjectures and principles will now be presented by initially describing their more salient features and then an attempt is made to separate these conjectures and principles into their respective characteristics, procedures and arguments by using a table.

\section{Initial exposure}

Face-to-face facilitation supported by a printed handout that contains a step-by-step guide to developing a functional expert system are characteristics of the students' initial exposure to a learning environment that uses computer technology as a cognitive tool to facilitate higher order thinking. The face-to-face facilitation should preferably be the medium used to demonstrate a worked example of a functional expert system. A printed handout that corresponds to the steps used or explained in the demonstration should compliment this demonstration. Table 1 provides a summary of the characteristics, arguments and procedures associated with the conjectures and principles concerning the students' initial exposure to the learning environment.

Table 1

Summary of conjectures and principles concerning the students' initial exposure to the learning environment

Characteristics

- $\quad$ Face-to-face facilitation.

- $\quad$ Printed handout to support faceto-face facilitation.

Procedures

- Demonstration involving worked examples.

- Complimented by a printed handout containing a step-bystep guide to support understanding. Argument

- Just-in-time support through face-to-face interaction.

- Handouts serve as a supporting instrument to enhance understanding as well as a reference to be used later.

\section{Students discovering concepts for themselves}

A number of characteristics that filter through the learning environment developed during this study involve allowing or encouraging students to discover information by themselves. This is achieved by providing them with basic or fundamental information, restricting them to the exploration of concepts in manageable chunks, allowing them to struggle unaided for a limited period of time and encouraging them to consider their mistakes to be part of the learning process. These characteristics resonate with many of the properties of a guided discovery learning environment, which allows for a regulated or balanced amount of assistance from the facilitator and for resources to be made available to the students when they need it. By monitoring the students' progress, the facilitator is able to prevent the students from encountering an irreconcilable impasse and ensures that the learning objectives are achieved. Table 2 provides a summary of the conjectures and principles related to the students discovering concepts on their own by separating these conjectures and principles into their characteristics, procedures and arguments. 
Table 2

Summary of design principles concerning the students discovering information on their own

\begin{tabular}{|c|c|c|}
\hline Characteristics & Procedures & Argument \\
\hline 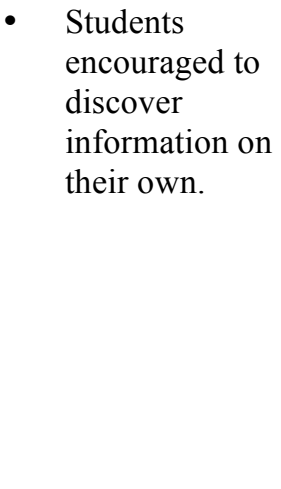 & $\begin{array}{l}\text { Providing students with } \\
\text { basic/foundational information } \\
\text { Allowing students to struggle } \\
\text { on their own for a limited } \\
\text { period. } \\
\text { Encourage students to view } \\
\text { mistakes as part of the } \\
\text { learning process. } \\
\text { Allowing students to explore } \\
\text { concepts in manageable } \\
\text { chunks. } \\
\text { Monitor student's progress. }\end{array}$ & 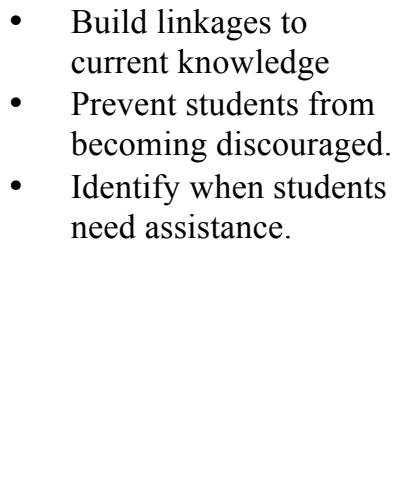 \\
\hline
\end{tabular}

\section{Designing the expert system on paper}

Formulating questions and flowcharts are some of the activities included in the learning environment that involves designing an expert system in order to represent understanding. These activities are preceded by exercises that assist the students in becoming familiar with the flow-diagram symbols and then encouraging them to plot the logic of their expert systems on paper in the form of a flow-diagram. This would have the effect of reducing the cognitive load involved in designing the system, as students would not have to be limited or distracted by the challenges involved in using the expert system shell software. This would also give them the opportunity to articulate their understanding of the expertise the expert system is designed to imitate. Table 3 provides a summary of the conjectures and principles related to designing the expert system on paper by separating them into their characteristics, procedures and arguments.

Table 3

Summary of conjectures and principles concerning the students designing their expert systems on paper

\begin{tabular}{|c|c|c|}
\hline Characteristics & Procedures & Argument \\
\hline 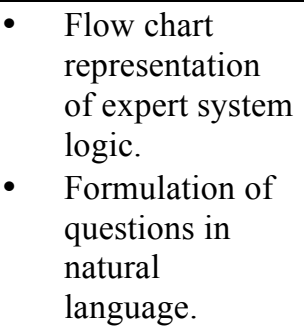 & $\begin{array}{l}\text { Familiarise students with flow } \\
\text { chart symbols. } \\
\text { - Use non-laboratory contact } \\
\text { - } \quad \text { Eessions for design. } \\
\text { Encourage students to plot the } \\
\text { expert system on paper first. }\end{array}$ & $\begin{array}{l}\text { - } \\
\text { Reduces cognitive } \\
\text { load. } \\
\text { Articulates } \\
\text { understanding of } \\
\text { expertise. } \\
\text { Able to compare and } \\
\text { contrast understanding } \\
\text { with group members. }\end{array}$ \\
\hline
\end{tabular}

\section{Creating subject domain awareness}

The characteristics associated with creating an awareness of the subject domain involve exploring the students' current understanding, paper based exercises, providing suitable support and using video clips to conceptualise learning. The students' current understanding can be explored through discussion and brainstorming sessions, where the facilitator allows the student group to lead or guide the discussion. Paper based completion exercises; multiple-choice items and open-ended questions could also facilitate the exploration of the domain and allow the students to gain a suitable insight into various concepts associated with it. Support could be provided by avoiding assumptions regarding the students' understanding and allowing the students to ask questions freely. Video clips depicting realistic communications situations could be used to situate the learning in a realistic or authentic setting. Learning points and conceptual understanding could be rooted in these realistic situations. Paper based exercises and group discussions could reference these 
realistic situations to reinforce conceptual understanding. It is, however, important to allow the students themselves to uncover concepts and for the facilitator to adopt a more constructivist approach during class discussions. Table 4 provides a summary of the conjectures and principles related to creating domain awareness by separating them into their characteristics, procedures and arguments.

Table 4

Summary of conjectures and principles concerning creating domain awareness

Characteristics

Procedures

- Exploration of - Brainstorming, group students' discussion and paper based existing knowledge.

- Using paper based exercises.

- $\quad$ Providing support.

- Using video clips depicting realistic situations. exercises involving multiple choice items, completion exercises and open-ended questions.

- Make use of examples.

- Allow students to ask questions freely, clarify concepts and adopt a constructivist approach to allow students to uncover learning points on their own.

- Showing students video clips to situate learning in realistic settings that they can reference during discussions.

\section{Argument}

- Exploring the students' current understanding would allow the facilitator to gain an insight into where to pitch explanations and instruction.

- Examples would make the learning points less abstract and alleviate cognitive load.

- Allowing students to uncover learning points on their own would facilitate a deeper understanding of concepts associated with the domain.

\section{Creating an awareness of the relationship between a conceptual understanding and a representation of that understanding}

The conjectures and principles associated with the representation of understanding involved the following:

- Activities designed to bridge the gap between a conceptual understanding and a representation of that understanding.

- Formulating appropriate questions.

- Formulating inferences.

- Modelling understanding through the development of a functional expert system.

To seamlessly bridge the gap between a conceptual understanding and a representation of that understanding, a flow-diagram representation of a group discussion, involving a communications situation, could be drafted immediately after or as the discussion takes place. This would allow the students to view this flow diagram as an authentic and reliable representation of their understanding and enable them to relate to the logic or utility behind this form of representation. Due to the possibility that the representation of understanding using an algorithmic flow-diagram may place high cognitive demands on the student, owing to unfamiliarity with the flow-diagram symbols and logic, it would be useful to initially draft questions and answers to these questions. These can them be converted into a flow-diagram. The formulation of inferences is an important component of the students' representation of understanding. These inference formulations should be carefully monitored by the facilitator to ensure that they are not merely an aggregation of answers to various questions. An important component of the students' modelling of conceptual understanding involves the development of a functional expert system. This development would encourage them to explore their conceptual understanding of the subject domain more comprehensively. Table 5 provides a summary of the conjectures and principles 
related to the representation of conceptual understanding by separating them into their characteristics, procedures and arguments.

Table 5

Summary of conjectures and principles concerning the students' representation of conceptual understanding

Characteristics

- $\quad$ Bridging the gap

between

conceptual

understanding

and a

representation

of that

understanding.

- Formulating questions and answers.

- Formulating inferences

- Developing a functional expert system

Procedures

- Creating contiguity between discussion and representations

of that discussion.

- Encouraging students to formulate questions in order to probe for understanding.

- Explaining to students the distinction between the aggregation of options and making inferences based on options selected. Argument

- The contiguity allows students to appreciate the logic involved in representing understanding.

- The contiguity encourages students to consider the representation to be a true reflection of their understanding.

- An inference is a conclusion drawn from available facts and constitutes the display line or the output of the fictional expert system.

\section{Students' development of a functional expert system}

The students were encouraged to represent their understanding of communications concepts through the development of a functional expert system. The following characteristics are associated with this component of the learning environment:

- Orientation to the learning environment

- Group collaboration

- Relating the development to the flow diagram representation

- Becoming familiar with how to use the expert system shell

- The students' active participation in the development process

- Reflecting expert system logic

Face-to-face facilitation, worked examples and group collaboration are components of the students' orientation to the learning environment that requires them to develop a functional expert system. Face-to-face facilitation allows the facilitator to provide the students with prompt support. Worked examples lessen the cognitive load by making concepts less abstract and group collaboration allows for peer support and the exchange of ideas. By basing the development of a functional expert system on the flow-diagrams formulated by the students, the students are encouraged to revisit their ideas and conceptual understanding and explore them at a deeper level. Familiarity with the development environment (expert system shell) is important and the facilitator must not assume that they have sufficient knowledge in this regard. It is important for facilitators to monitor the students' development and to ensure that this development reflects expert system logic by making inferences and not merely aggregating options selected. This can be done by asking questions and allowing students to explain or explicate the logic on which their development is based. Table 6 provides a summary of the conjectures and principles related to the development of a functional expert system by separating them into their characteristics, procedures and arguments. 
Table 6

Summary of design principles concerning the students' development of a functional expert system

\begin{tabular}{|c|c|c|}
\hline Characteristics & Procedures & Argument \\
\hline $\begin{array}{ll}\text { - } & \text { Orientations } \\
\text { measures } \\
\text { - Collaborating in } \\
\text { groups } \\
\text { Relating expert } \\
\text { system } \\
\text { development to } \\
\text { flow diagram } \\
\text { representation/des } \\
\text { ign } \\
\text { Familiarity with } \\
\text { the expert system } \\
\text { shell } \\
\text { Active } \\
\text { participation } \\
\text { Reflecting expert } \\
\text { system logic }\end{array}$ & $\begin{array}{l}\text { Face-to-face facilitation. } \\
\text { - } \quad \text { Using worked examples. } \\
\text { - } \\
\text { Encor collaboration. } \\
\text { development on flow diagram } \\
\text { design. } \\
\text { Assumptions regarding the } \\
\text { student's ability to use the } \\
\text { development software must be } \\
\text { avoided. } \\
\text { Pose questions to gauge level } \\
\text { of understanding. }\end{array}$ & $\begin{array}{ll}\text { - } & \text { Timely response to } \\
\text { students concerns. } \\
\text { - } & \text { Lesson cognitive load. } \\
\text { Peers support each } \\
\text { other. } \\
\text { - } \\
\text { Students are } \\
\text { encouraged to explore } \\
\text { their understanding } \\
\text { more deeply when they } \\
\text { revisit flow-diagram } \\
\text { design. }\end{array}$ \\
\hline
\end{tabular}

\section{Students' engagement with the problem statement}

The students' engagement with the problem statement is an important part of the learning environment developed during this study. The following characteristics are associated with the students' engagement with the problem statement that formed part of the learning environment:

- Preferably situated in a real life or authentic setting.

- Presented to the students in the form of a brief and not a detailed description of a scenario with an obvious or implied solution.

- The ill-structured problem must be designed in such a way that allows for the specific concepts to emerge.

- The facilitator must be on hand to provide prompt support.

Presenting the problem statement to the students in the form of a brief that contains a conceptual outline that can be applied to a variety of situations allows the problem to be open ended in nature. The problem would then accommodate a variety of possible solutions and would give the students the space to explore their own understanding at a deeper level. The facilitator must be on hand to provide support but must do so by posing thought provoking questions rather than imposing his or her own ideas on the student. Table 7 provides a summary of the conjectures and principles related to the students' engagement with the problem statement by separating them into their characteristics, procedures and arguments. 
Table 7

Summary of conjectures and principles concerning the students' engagement with the problem statement

\begin{tabular}{|c|c|c|}
\hline Characteristics & Procedures & Argument \\
\hline 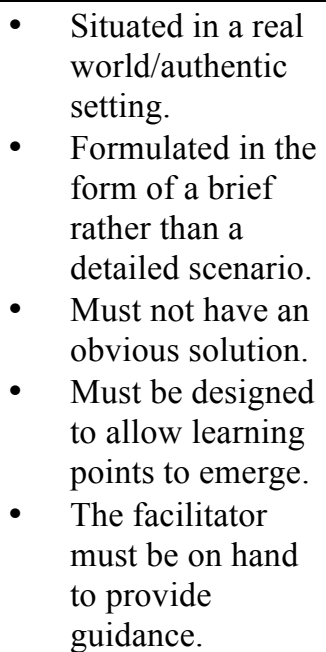 & $\begin{array}{l}\text { - Design in the form of a brief } \\
\text { that outlines a concept and } \\
\text { not a particular situation. } \\
\text { Concepts should be } \\
\text { applicable to an authentic } \\
\text { setting. } \\
\text { The facilitator must monitor } \\
\text { the students' engagement to } \\
\text { ensure learning points } \\
\text { emerge and that they do not } \\
\text { reach an irreconcilable } \\
\text { impasse. } \\
\text { The facilitator should pose } \\
\text { questions to stimulate } \\
\text { thinking. }\end{array}$ & $\begin{array}{l}\text { - Allow the students to } \\
\text { explore their own } \\
\text { understanding and gain } \\
\text { a deeper conceptual } \\
\text { grasp of subject matter. } \\
\text { The open-ended nature } \\
\text { of the problem will } \\
\text { allow for multiple } \\
\text { solutions. } \\
\text { The facilitator will not } \\
\text { impose their ideas on } \\
\text { the students. }\end{array}$ \\
\hline
\end{tabular}

\section{Discussion and literature reflection}

What follows is a discussion of the findings applicable to this study together with an attempt to link these findings to the relevant literature. This discussion and literature reflection will be organised under the following headings:

- Students left to discover information on their own

- $\quad$ Practical application of understanding

- Making connections with existing knowledge

- Collaborating in groups

- Representing understanding and knowledge

- Developing a functional application

- $\quad$ Exploring an ill-structured problem

- Alleviating cognitive load

\section{Students left to discover information on their own}

Many of the conjectures and principles formulated during this research involved students being left to discover information and arrive at a conceptual understanding of concepts applicable to the domain largely on their own. A limited amount of measured guidance is regarded as appropriate assistance or support for the learners during this process. This resonates with many ideas reflected in the literature concerning discovery learning and guided discovery-learning environments.

In a pure discovery-learning environment, students are left to figure out solutions to challenges on their own with little or no guidance from an instructor (Prince \& Felder, 2007). Students are principally responsible for finding or discovering the "properties of a domain" when working within a discovery-learning environment (Gijlers \& de Jong, 2005; p. 265). These properties are not made available to the students in a direct manner. The students are to use interpretation and experimentation to discover them (Gijlers \& de Jong, 2005). The environment provides very little structure within which the learning takes place and the students are encouraged to explore solutions through a trial and error approach (Prince \& Felder, 2007). The idea that 
students consider their mistakes to be an opportunity to gain an enhanced understanding of communications concepts is a significant component of the conjectures and principles that informed the design of the learning environment. The emphasis is not on correct answers or on definitive representations of understanding, but rather on individual explorations and constructive representation of knowledge. This is supported by Gilakjani et al. (2013; p. 50) who state that "it is important for the teacher to utilize errors as a way of providing feedback for the learner's understanding". Liu et al. $(2013$; p. 2) point out that "feedback is essential for scaffolding conceptual change" especially when engaging with an unfamiliar topic. Students are encouraged to learn extra information beyond that which is made available by the lecturer through a challenging process of exploration and discovery. A student who was exposed to a learning environment based on the design principles formulated during this study had the following to say: "I think in the end you will remember this, after all the battling and the crying, you will remember it better than if a lecturer just stands in front of you and actually tells you what to do".

It was, however, concluded that to allow students to struggle on their own for too long could become demoralizing and counterproductive. The conjectures and principles formulated during this study were, therefore, more closely aligned to a guided discovery-learning approach rather than a pure discovery learning one. In a guided discovery-learning environment, there is a measured amount of structure and the facilitator offers a calculated amount of guidance to the students (Prince \& Felder, 2007).

The conjectures and principle formulated in this study advise that it is necessary for students to have a certain amount of foundational or fundamental knowledge if they are to function successfully within an environment that requires them to discover information on their own. Prior or existing knowledge has an important influence over knowledge development in a discovery learning process (Gijlers \& de Jong, 2005).

Ifenthaler (2012; p. 48) proposes that a technique for "guiding and supporting the regulation of learners' problem-solving processes is prompting". These can be "presented as simple questions, incomplete sentences, explicit execution instructions", etc. Prompts are of a generic or direct nature, where generic prompts encourage learners to pause and "reflect about their current activities" Direct prompts present learners with "expert models of reflective thinking". Ifenthaler (2012; p. 48) further determined that, although direct prompts could assist people with underdeveloped problem solving skills, they "seem to prevent learners from solving problems autonomously". Generic prompts, however, "guide learners to use a specific set of problemsolving strategies" and encourage the independent self-regulation of problem-solving activities.

\section{Practical application of understanding}

The practical demonstration of understanding is an important aspect of the learning environment designed during this research and many of the principles and conjectures were formulated to facilitate this type of activity. Edelson (2001; p. 358) suggests that being able to "retrieve and recite facts that are relevant to a problem" is of little use if a person is unable to "combine those facts to construct a solution to that problem". The students must learn how to use or operationalise conceptual knowledge if the knowledge is to be of any value (Edelson, 2001).

\section{Making connections with existing knowledge}

The principles and conjectures formulated during this research often involved an exploration of the students' existing knowledge before new concepts were introduced. The context within which the learning takes place together with making linkages to existing knowledge is alluded to by Edelson (2001). He proposes that connections that are constructed for subsequent retrieval when learning takes place are dependent on the context in which that learning takes place. The creation and elaboration of these indices or contextual cues are a decisive part of the learning process (Edelson, 2001). Rote learning and the simple regurgitation of facts are characteristic of lower order thinking while higher order thinking typically involves combining prior or existing knowledge with new or recently acquired knowledge in order to find solutions to confounding problems (Zoller \& Pushkin, 2007). 


\section{Collaborating in groups}

The environment designed during this research encouraged students to share understanding and offer support during the exploration and discovery of concepts and information. If students are to successfully investigate a domain within an environment that is based on discovery learning, measures should be in place to support "working in collaborative groups" (van Joolingen, de Jong, Lazonder, Savelsbergh, \& Manlove, 2005; p. 672). This would encourage higher achievement and lead to a deeper exploration of the subject domain. By collaborating in groups students are more likely to engage in a dialogue that contributes to meaningful learning. This dialogue is characterized by the "asking and answering of questions, reasoning and conflict resolution" (van Joolingen et al., 2005; p. 682). The process of critical thinking often suggests the comparing and contrasting of ideas, the classification and evaluation of information, and the evaluation of bias (Zoller \& Pushkin, 2007).

The construction of collective or shared knowledge is the decisive objective of collaborative learning. Van Joolingen et al. (2005; p. 683) argue that this objective has two important "consequences for the tools in collaborative discovery learning". These are:

- Shared knowledge must be explicitly represented or externalized so that learners can examine the object that is being discussed and explored.

- The tools used should accommodate or allow for the integration of the students' multiple perspectives.

\section{Representing understanding and knowledge}

Many of the principles and conjectures formulated involve characteristics, procedures and arguments that are a factor in enabling learners to represent their understanding by drafting flow diagrams and through the development of a functional expert system. Lee and Nelson $(2005$; p. 3$)$ propose that complex cognitive processes, such as problem solving, are enhanced and activated through the external representation of knowledge that could make use of symbols and objects. External representations have the potential to be an effective way of addressing complex problems as they help to clarify the fundamental statement of the problem, better its indistinct status to an "explicit condition", limit unnecessary cognitive activity and "generate multiple solutions" (Lee \& Nelson, 2005; p. 3). Furthermore, an external representation of understanding can be used as a means of clarifying or elaborating an individual's unique "conceptual understanding to others" as well as evaluating the learner's conceptual understanding (Lee \& Nelson, 2005; p. 3).

\section{Developing a functional application}

The expert system designs formulated in the form of flow diagrams, IF THEN statements and natural language during the non-computer integrated sessions were converted into functional expert systems during contact sessions in the computer laboratory. This often encouraged the students to revisit the logic of their designs and seemed to allow them to gain a deeper understanding of the concepts incorporated in them. It often became apparent to the students that their expert system designs were not functioning as inference engines that drew conclusions from available facts but were rather designed to aggregate options selected by a potential user. Computer technology that has the capacity to support the creative management and expression of ideas embraces the constructivist position concerning the active building of meaning (Kimber, Pillay, \& Richards, 2007). Computer technology used in this way enables knowledge to be constructed and reconstructed "progressively, repeatedly and with ease, complementing meta-cognitive processes visually and electronically" (Kimber et al., 2007). It, therefore, develops into a significant mechanism that supports the "generative learning process" (Kimber et al., 2007).

Developing a functional expert system provided students with the opportunity to re-evaluate their understanding of a particular problem. This is supported by the following quote from a student who was 
interviewed after working in a learning environment that was based on the design principles formulated during this study: "It is difficult because when you draft it on a page it is easier but when it comes to doing it practically it's very difficult because you have to have time and implement all the ideas that you have".

\section{Exploring an ill-structured problem}

An aspect of the learning environment developed during this research involved students engaging with an illstructured open-ended problem. The principles and conjectures formulated in regards to problem interaction and problem development revolved around situating the problem in a realistic context, ensuring the emergence of appropriate learning points, providing an appropriate and measured amount of guidance and ensuring that the problem statement did not contain an obvious solution. These principles and conjectures resonated notably with many of the characteristics of Problem Based Learning.

A characteristic of the problem that the students are asked to engage with is that it should be presented to them in the form of a brief rather than a specific scenario with an implied solution. The principles and conjectures regarding problem development clearly indicated that the problem statement should involve more of a conceptual predicament than an exercise that encouraged the students to search for a definitive answer. Problems are distinct from simple exercises in that they require more than simply "knowledge and the application of knowledge", but are conceptual dilemmas that may involve a number of cycles of "interpretation, representation, planning, deciding, execution, evaluation and re-evaluation" (Zoller \& Pushkin, 2007; p. 155). The productive and meaningful interaction with problems therefore calls for the application of higher order thinking skills and typically leads to a modified level of understanding rather than merely a resolution to the dilemma (Lyle \& Robinson, 2001; p. 443).

\section{Alleviating cognitive load}

An aspect of the scaffolding provided to the students involves presenting the students with examples of the various concepts explored in the learning environment as well as progressing from simple explanations and instances to more complex ones. This resonated with some of the principles associated with Cognitive Load Theory.

The conjectures and principles formulated during this research contained characteristics, procedures and arguments that were directed at allowing the students to progress from simple tasks to more complex ones. Examples of flow-diagrams that represented very simple decision structures should initially be presented to the students in order to explain the basic symbols used to represent understanding in this way and to introduce them to the logic behind using flow-diagrams. The flow-diagrams should become progressively more complex, involving multiple decision structures and partially completed diagrams. By progressing from simple tasks to more complex ones the intrinsic cognitive load associated with a particular undertaking can be reduced. The extraneous aspects of this undertaking can be reduced by initially "providing the substantial scaffolding of worked examples" (Paas, Renkl, \& Sweller, 2003; p. 3). These can be followed by "completion problems and then full problems" (Paas et al., 2003, p. 3). Paas et al. (2003; p. 3) further suggest that using worked examples, as an alternative to attempting to solve comparable problems, is a widely accepted and well-known technique aimed at reducing cognitive lead. The scaffolding provided by using worked examples can be reduced or faded by successively removing parts of the solution to the problem until eventually only a complete problem or completely unsolved problem remains (Paas et al., 2003).

\section{Conclusion}

Even though South Africa clearly has many unique educational challenges, issues related to academic underperformance are certainly not confined to this part of the world. It is, therefore, hoped that the findings presented in this study will find global relevance. Conjectures and principles formulated using an iterative design research approach are advanced to further our understanding of how computer technology can be used 
to facilitate higher-order thinking. It is important that educational scientists "develop technological tools, curriculum, and learning opportunities to seek specific results" (Zhang, 2013; p. 1). This would help to make research more relevant and also helps to create a distinction between applied educational research and other natural sciences (Zhang, 2013).

Computer technology has the potential to address some of the educational challenges faced by higher education in South Africa. It is, however important to recognize the situations in which educational technology are suitable and to identify the best way to use technology in these particular contexts (Jaffar et al., 2007). When using technology as a cognitive tool students are encouraged to act as designers and to represent their understanding so that it can be compared and contrasted, reflected on and articulated. This process is bound to facilitate a deeper, more meaningful level of learning and to encourage a higher level if thinking.

Using technology in the form of an expert system shell is one way in which computers can be used as a cognitive tool and is best suited to problems to which the solutions comprise suggestions based on a combination of decisions. There, however, seems to have been little research conducted into what a learning environment that uses technology as a cognitive tool in the form of an expert system shell should look like. This study developed conjectures and principles that may serve as a useful guide to lecturers and instructional designers who may wish to use technology as an expert system shell in a learning environment.

\section{References}

Dzubak, C. (2005). What skills and whose standards: Why are students underprepared? Synergy: The Journal of the Association of the Tutoring Profession, 1(1), 1-13.

Edelson, D.C. (2001). Learning-for-use: A framework for the design of technology-supported inquiry activities. Journal of Research in Science Teaching, 38(3), 355-385.

Fiske, E. B., \& Ladd, H. F. (2005). Racial equality in education: How far has South Africa come? Special issue of International journal of educational development, Terry Sanford Institute of Public Policy.

Gijlers, H., \& de Jong, T. (2005). The relation between prior knowledge and students' collaborative discovery learning process. Journal of Research in Science Teaching, 42(3), 264-282.

Gilakjani, A. P., Leong, L,. \& Ismail, H. N. (2013). Teachers' use of technology and constructivism. I.J. Modern Educational and Computer Science, 4, 49-63.

Ifenthaler, D. (2012). Determining the effectiveness of prompts for self-regulated learning in problem-solving scenarios. Educational Technology \& Society, 13(1), 38-52.

Jaffer, S., Ng'ambi, D., \& Czerniewicz, L. (2007). The role of ICTs in higher education in South Africa: One strategy for addressing teacher and learning challenges. International Journal of Education and Development using Information and Communication Technology, 3(4),131-142.

Jonassen, D. H. (1995). Operationalizing mental models: Strategies for assessing mental models to support meaningful learning and design-supportive learning environments. Proceedings of the Computer Supported Collaborative Learning Conference

Jonassen, D. H. (2006). Modeling with technology: Mindtools for conceptual change (3rd ed.). Upper Saddle River: Pearson Merrill Prentice Hall.

Jonassen, D. H., Carr, C., \& Yueh, H. (1998). Computers as mindtools for engaging learners in critical thinking. TechTrends, 43(2), 24-32.

Jonassen, D. H., \& Reeves, T. C. (1996). Learning with technology: Using computers as cognitive tools. In D. H. Jonassen (Ed.). Handbook of research on educational communications and technology, pp. 693-719. New York: Macmillan.

Jones, N. H., Ross, H., Lynam, T., Perez, P., \& Leitch, A. (2011). Mental models: An interdisciplinary synthesis of theory and methods. Ecology and Society, 16(1), 46-58.

Kennedy, D. M., \& McNaught, C. (2001). Computer-based cognitive tools: Description and design. In Montgomerie, C., \& J. Viteli (Eds.), ED-MEDIA 2001, pp. 925-930. Proceedings of the 13th Annual World Conference on Educational Multimedia, Hypermedia \& Telecommunications. Tampere, Finland, 25-30 June. Norfolk, VA: Association for the Advancement of Computers in Education (AACE). 
Kimber, K., Pillay, H, K., \& Richards, C. (2007). Techno-literacy and learning: An analysis of the quality of knowledge in electronic representations of understanding. Computers and Education, 48(1), 59-79.

Kirscher, P., \& Wopereis, I. G. J. H. (2003). Mindtools for Teacher Communities: A European perspective. Technology, Pedagogy and Education, 12(1), 105-124.

Lee, Y., \& Nelson, D. W. (2005). Design of a cognitive tool to enhance problem-solving performance. Educational Media International, 42(1), 3-18.

Liu, M., Horton, L., Lee, J., Toprac,. P, Yuen, T. T., \& Bogard, T. (2013). Designing technology-enriched cognitive tools to support young learners' problem solving. The International Journal of Cognitive Technology.

Lyle, K. S., \& Robinson, W. R. (2001). Teaching science problem solving: an overview of experimental work. Journal of Chemical Education, 38(4), 442-468.

McLoughlin, C. (1999). The implications of the research literature on learning styles for the design of instructional material. Australian Journal of Educational Technology, 15(3), 222-241.

Nieveen, N. (2007). Formative evaluation in educational design research. Proceedings of the seminar conducted at the East China Normal University, Shanghai, November 23-26, 2007.

Paas, F., Renkl, A., \& Sweller, J. (2003). Cognitive load theory and instructional design: Recent developments. Educational Psychologist, 38(1), 1-4.

Palermo, J., Marr, D., \& Oriel, J., Arthur, J,. \& Johnston, D. (2012). Tracking students success: Using and action learning approach to better understand the how, what, where and why. Journal of Institutional Research, 17(1), 39-50.

Parker, J. (2011). A design-based research approach for creating effective online higher education courses. Paper presented at 26th Annual Research Forum: Educational Possibilities. 13 August 2011, University of Notre Dame, Fremantle.

Plomp, T. (2007). Educational design research: An introduction. Proceedings of the seminar conducted at the East China Normal University, Shanghai, November 23-26, 2007.

Prince, M. J., \& Felder, R. M. (2007). The many faces of inductive teaching and learning. Journal of College Science Teaching, 36(5), 14-20.

Reeves, C. T., McKenney, S., \& Herrington, J. (2011). Publishing and perishing: The critical importance of educational design research. Australasian Journal of Educational Technology, 27(1), 55-65.

Silburn, J., Earnest, J., Butcher, L., \& de Mori, G. (2008). Needs analysis of students from refugee backgrounds: A case study from Murdoch University, Western Australia. AARE 2008 Conference.

Spector, J. M., Lockee, B. B., Smaldino, S. E., \& Herring, M. C. (2013). Learning, problem solving, and mind tools: Essays in honor of David H Jonassen. Routledge, New York.

Stephen, D. F., Welman, J. C., \& Jordaan, W. J. (2004). English language proficiency as an indicator of academic performance at a tertiary institution. SA journal of human resource management, 2(3), 42-53.

Thanasoulas, D. (2001). Constructivist learning. Retrieved 5 October, 2008 from http://www.eltnewsletter.com/back/April2001/art542001.htm

van Joolingen, W. R. (1999). Cognitive tools for discovery learning. International Journal of Artificial Intelligence in Education, 10(3), 385-397.

van Joolingen, W. R., de Jong, T., Lazonder, A. W., Savelsbergh, E. R., \& Manlove, S. (2005). Co-Lab: research and development of an online learning environment for collaborative scientific discovery learning. Computers in Human Behavior, 21(4), 671-688.

Vosniadou, S. (2007). The Cognitive-Situative Divide and the Problem of Conceptual Change. Educational Psychologist, 42(1), 1-32.

Vosniadou, S. (2008). International handbook of research on conceptual change. Educational Psychology Handbook Series. University of Maryland. London: Routledge.

Vosniadou, S., Ionnides, C., Dimitrakopoulou, A., \& Papademetriou, E. (2001). Designing learning environments to promote conceptual change in science. Learning and Instruction, 11(4), 381-419.

Zhang, L. (2013). A meta-analysis method to advance design technology-based learning tool: Combining qualitative and quantitative research to understand learning in relation to different technology features. Journal of Science, Education and Technology,16(4), 1-15.

Zoller, U., \& Pushkin, D. (2007). Matching Higher-Order Cognitive Skills (HOCS) promotion goals with problem-based laboratory practice in a freshman organic chemistry course. Chemistry Education Research and Practice, 8(2), 153-171. 
Australasian Journal of Educational Technology, 2014, 30(4).

Corresponding author: Gary W. Collins, gary@webzoo.co.za

Australasian Journal of Educational Technology (C) 2014.

Please cite as: Collins, G.W., \& Knoetze, J.G. (2014). Information communication technology in the form of an expert system shell as a cognitive tool to facilitate higher-order thinking. Australasian Journal of Educational Technology, 30(4), 455-471. 